\title{
The Frequency of the Delay of Puberty and Various Developmental Disorders in Adolescents in Namangan and Jizzakh Regions of the Republic of Uzbekistan on the Data of Screening in 2021 Year
}

\author{
Mavlonov UKh ${ }^{1}$, Urmanova Yu ${ }^{2 *}$, Aliyeva $\mathrm{DA}^{3}$ and Dalimova $\mathrm{GA}^{4}$ \\ ${ }^{1}$ Bukhara Regional Endocrinological Dispensary, RUZ, Bukhara \\ ${ }^{2}$ Department of Endocrinology, Tashkent Pediatric Medical Institute, RUZ, Tashkent, Mirzo-Ulugbek \\ ${ }^{3}$ Department of Neuroendocrinology, Acad. Yosh. Turakulova, RUZ, Tashkent, Mirzo-Ulugbek \\ ${ }^{4}$ Endocrinology Department of the RSNPMC Endocrinology, Acad. Yosh. Turakulova, RUZ, Tashkent, Mirzo-Ulugbek \\ *Corresponding author: Urmanova Yulduz Makhkamovna, Republican Specialized Scientific-Practical Medical Center \\ Endocrinology named by Acad. Yo. Kh. Turakulov, Department of Neuroendocrinology, Tashkent Pediatric Medical Institute \\ (Department of Endocrinology), Bukhara Regional Endocrinology Dispensary, Republic of Uzbekistan
}

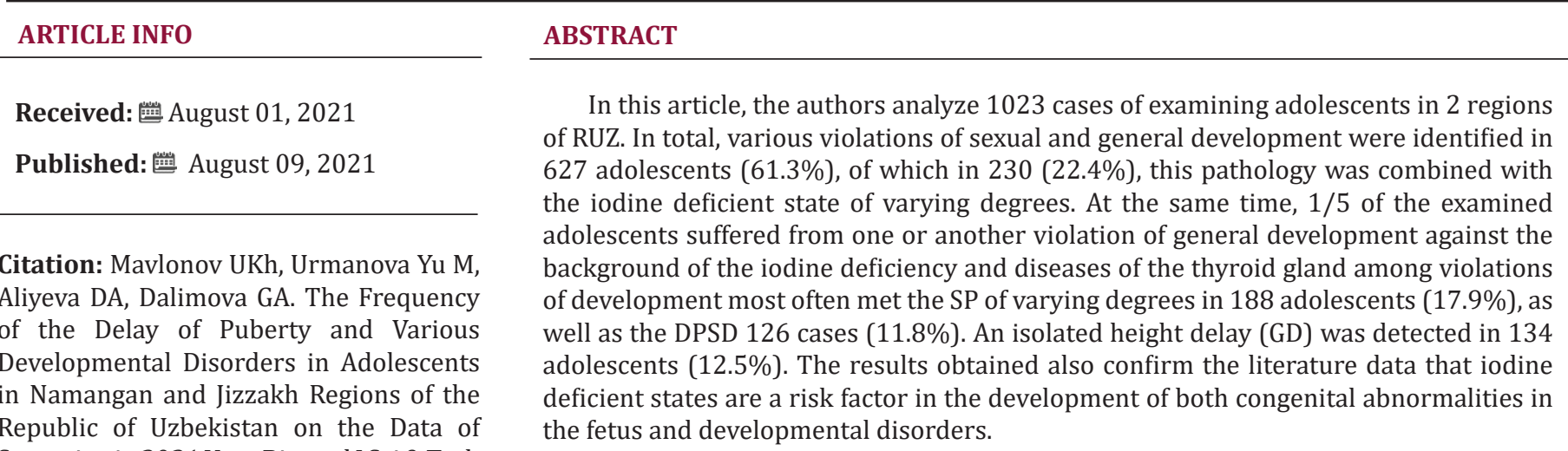

Keywords: Puberty Delay; Screening; Frequency

\section{Introduction}

The Delay of Puberty (DP) implies the absence of secondary sexual signs and relevant physical changes in boys and girls aged 14 years. The delay in sexual development in the boys implies the lack of an increase in the testicular volume $(<4 \mathrm{ml})$ and if the length of the testicles do not reach $2.5 \mathrm{~cm}(<4 \mathrm{ml})$ at the age of 15 years. The main signs of the delay of sexual development in girls is the lack of Telarche and Adrenarche by the 13 years and the absence of Menarche by 15 years [1-3]. In accordance with the ICD-10, the delay of sexual development is highlighted as an independent endocrine disease. DP is one of the actual problems of endocrinology. Even though the frequency of the recovery of the DP among both sexes is the same, but boys are more often treated with complaints: 9: 1 [4,5]. At the same time, in modern literature there is not enough data in this area, there are no work and fully dedicated to the epidemiology of various forms of DP in boys and girls. There are many publications on separate only issues. There are no multicenter studies of DP in boys and girls in any foreign literature, nor in the near abroad over the past few decade. 
According to the researchers, the frequency of the DP is from $0.4 \%$ to $9.8 \%$, and over the past decades its increase is noted. Such a variation of the frequency of the DP is associated with the lack of clear criteria for the age limits of the puberty and possible hyperdiagnosis. The role of the thyroid gland in the regulation of the reproductive function is clearly visible both in the norm and especially with its functional disorders by type of hyper and hypothyroidism. The excess T3 and T4 leads to an increase in the LH, suppressing the hormone ovulatory peak, the lack of lutein phase, the disorders of the menstrual cycle and infertility. With a shortage of thyroid hormones, the biosynthesis of FSH and LH decreases, the function of the genital glands is oppressed with all further manifestations of their insufficiency [6-17]. According to WHO estimates, about two billion people are at risk of iodine deficiency in the sense that these people get an insufficient amount of iodine with food and water, thus undergoing risk of developing diseases caused by iodine deficiency. This risk is subject to both developed countries and developing (de Benoist et al. 2008). Independently delayed sexual maturation, also known as a constitutional delay in growth and puberty, represents the extreme end of the normal period of puberty and is the most common cause of DPs both in boys and girls. Family self-limited DP has a clear genetic basis. Nevertheless, the underlying neuroendocrine pathophysiology and genetic regulation is largely unknown. Most recently, new opening of genes from the sequencing studies of the next generation made it possible to understand genetic mutations that lead to a family DP. The results of these studies suggest that the genetic basis of the DP is likely to be very inhomogeneous. Anomalies for the development of Gonadoliberins neurons, their functions and paths downstream, metabolic and energy homeostatic disorders and transcriptional regulation of the axis of the hypothalamus-hypophysis-gonad may result in DP. This variety of different pathogenic mechanisms affecting the liberation of "brakes" of puberty may occur in several age windows between the fetus life and sexual ripening [11,13].

All of the above served as a reason for the present study.

The Purpose of the Study: is to study the frequency of the delay of Puberty and various developmental disorders in adolescents (boys and girls) in some regions of the Republic of Uzbekistan.

\section{Material and Methods}

We have been examined and surveyed in the framework of screening from all over the period from January 1, 2021 to April 1, 2021 - 1023 boys and girls in the 2 regions of RUZ - 523 adolescents were inspected in the Jizzakh region, 500 adolescents in the Namangan region Aged 11 to 15 years old. The main contingent was students of colleges and schools. All 1023 adolescents were performed by all anthropometric studies based on the international growth of Tanner-Weithause, the assessment of the stage of Pubert at on J. Tanner, if necessary, patients were sent to add-on-x-ray (radiograph of brush, CT / MRI of the Turkish saddle), ultrasound of genital organs, karyotype , Surgeon consultation, genetics, etc. Of the 1023 inspected were selected and surveyed in the future, 627 patients (61.3\%) with various developmental impairments, among which the DP was detected in 188 adolescents $(18.3 \%$ of the total number of viewed). In the future, all 188 patients a spectrum of research was performed, including the study of endocrine status, generalization, biochemical, hormonal (STG, LG, FSH, Prolactin, $\mathrm{TSH}$, testosterone, cortisol, free thyroxine, etc. - in the laboratory of radio immune hormonal studies of the RUS. The study was carried out in the framework of the project. These groups of control of the appropriate age and gender for hormonal research were provided by the head. Lab. Hormonal RIA Research of RSNPMC Endocrinology MZ RUZ - K.M.N. Abdurakhmanova A.M. (Methodical recommendations).

The obtained data was processed using Microsoft Excel and Statistica_6 computer programs. The average values (M) were calculated, the standard deviations of the average (M). The accuracy of differences in the level between groups was estimated by the value of the confidence interval and the CTYUDENT criterion (P), quantitative on Wilcoxon. Differences were considered statistically significant at $\mathrm{p}<0.05$. This study was done in the framework of the project of the Ministry if Innovation of RUz.

\section{Results}

An examination of 1023 adolescents contributed to the diagnosis of various forms of delay and violations of sexual development. Table 1 shows the distribution of inspected adolescents by age - the stages of Puberty by J. Tanner. In the history of inspected adolescents, there were many different risk factors, among which the leading place occupies neuroinfection, then viral hepatitis and in third place in frequency - chickenpox. Table 2 shows the frequency of the delays of puberty and various developmental disorders among 1023 adolescents. As can be seen from Table 2, among violations of development, there were most often DP of varying degrees in 188 adolescents (18.3\%), as well as the DPSD of 126 cases (11.8\%). An isolated height delay (SR) was detected in 134 adolescents (12.5\%). Of the 1023 inspected were selected and surveyed in the future, 627 patients (61.3\%) with various developmental impairments, among which the DP was detected in 188 adolescents (18.3\% of the total number of viewed). 
Table 1: Distribution of patients by floor and age (5 stages of Puberty by J. Tanner).

\begin{tabular}{|c|c|c|c|c|c|}
\hline \multirow{3}{*}{$\begin{array}{c}\text { The stages of Puberty } \\
\text { by J. Tanner. }\end{array}$} & \multirow{3}{*}{ Age, years } & \multicolumn{4}{|c|}{ Total , $\mathrm{n}=1023$} \\
\hline & & \multicolumn{2}{|c|}{ A } & \multicolumn{2}{|c|}{ Б } \\
\hline & & $\mathbf{n}$ & DP & n & DP \\
\hline I & Prepuberty & $10 / 11$ & - & $23 / 26$ & - \\
\hline II & $11,7 \pm 1,3$ years & $40 / 52$ & $4 / 5$ & $65 / 61$ & $10 / 10$ \\
\hline III & $13,2 \pm 0,8$ years & $30 / 40$ & $8 / 13$ & $43 / 40$ & $20 / 22$ \\
\hline IV & $14,7 \pm 1,1$ years & $36 / 40$ & $10 / 6$ & $38 / 42$ & $9 / 11$ \\
\hline $\mathrm{V}$ & $15,5 \pm 0,7$ years & $65 / 75$ & $12 / 10$ & $90 / 95$ & $17 / 18$ \\
\hline \multicolumn{2}{|c|}{ Total - 1023} & 500 & 70 & 523 & 118 \\
\hline
\end{tabular}

Note: A - Namangan region, B - Jizzakh region, $\mathrm{N}$ is the number of patients in the region, $\mathrm{ZP}$ - the number of patients with the DP. Numerator - Boys, denominator - Girls

Table 2: The frequency of DP and various developmental disorders in adolescents from 2 regions.

\begin{tabular}{|c|c|c|c|}
\hline \multirow{2}{*}{ No } & \multirow{2}{*}{ Вид нарушения развития } & A & N (\%) \\
\cline { 3 - 4 } & & $49(14,3 \%)$ & $106(18,5 \%)$ \\
\hline 1 & DP & $24(6,9 \%)$ & $55(10,5 \%)$ \\
\hline 2 & GD & $24(6,9 \%)$ & $81(15,5 \%)$ \\
\hline 3 & DPSD & $4(1,2 \%)$ & $1(0,2 \%)$ \\
\hline 4 & DPED & $1(0,3 \%)$ & $1(0,2 \%)$ \\
\hline 5 & SDD & $-1(0,2 \%)$ \\
\hline 6 & WD & $64(18,7 \%)$ & $1(0,2 \%)$ \\
\hline 7 & Дефицит веса & $2(0,6 \%)$ & - \\
\hline 9 & PSMDD & $1(0,3 \%)$ & - \\
\hline 10 & PMDD & $1(0,3 \%)$ & - \\
\hline
\end{tabular}

Note: GD: Growth Delay; DP: Delay of Puberty; DPSD: Delay in Physical and Sexual Development; DPED: Delay of Psycho-Engine Development; SDD: Speech Development Delay; PP: Precocious Puberty; WD: Weight Deficiency; PSMDD: Physical Sexual and Mental Development Delay; PMDD: Physical and Mental Development Delay; PMSDD: A Delay in Psycho-Motor and Speech Development; GHD: Growth Hormone Deficiency

\section{Discussion}

So, from the examined patients, we revealed 188 (18.3\%) adolescents aged 11-15 years, suffering from the DP to varying degrees. At the same time, 13 patients identified a constitutional delay in DP, characterized by shorterness. Thus, by summing up the above analysis of the studies of the research in some regions of RUZ, it can be noted that such studies must be carried out as a screening and monitoring of adolescents for the purpose of early diagnosis of various anomalies of the reproductive sphere and the overall development of adolescents in the conditions of iodine deficiency.

\section{Conclusions}

a) The total violations of sexual and general development were identified in 627 adolescents (61.3\%) b) Among the violations of development, the RCPs of varying degrees were most often between 188 adolescents (17.9\%), as well as the DPSD of 126 cases (11.8\%). An isolated height delay (GD) was detected in 134 adolescents (12.5\%).

\section{References}

1. Bruno de Benua (2011) Elimination of iodine deficiency is one of the key health problems. Int Endocrinol J 6(38): 12-18.

2. Godina EZ, Zadorozhnaya LV, Khomyakova IA, et al. (2006) Features of the somatic development of children and adolescents in the conditions of iodine deficit (according to the materials of the population of the Saratov region). In: The physiology of the growth and development of children and adolescents. Eds: Baranova AA, Sheplyagina LA. Gootar Media pp.181-231.

3. Dedov II, Tulipakov AN, Peterkova VA (1998) Somatotropic insufficiency. Moscow, pp: 250. 
4. Ismailov SI, Nugmanova LB, Rasulov SF (2005) Dynamic analysis of the situation on the prevention of iodine deficient states in Uzbekistan. J Problem Biol Honey 3: 3-6.

5. Ismailov SI, Alimjanov NA, Rashitov MM (2005) Dynamics of the number and volume of surgical operations of the nodal forms of goiter in the conditions of iodine and iodine deficiency in Uzbekistan. Logs of Biol and Honey 3: 11-15.

6. Maullov UKh, Urmanova YuM (2015) Dynamics of anthropometric and hormonal indicators in adolescents (boys) with a delay in physical and sexual development against the background of therapy with drugs of the thyroid gland. Int Endocrinol Ukraine 1(65): 116-120.

7. Kurmachev NA (2012) Role and Tasks of pediatricians in the prevention of iodine deficient diseases in children. Pediatrics 2: 11-15.

8. Koltun VZ, Skorchuryakova JiA, Lobkin EN, Tail OI (2005) Ways to increase the mental performance of schoolchildren in the iodineic region. Hygiene and Sanitation 5: 52-54.

9. Troshina EA (2010) Correction of iodine deficiency in children Moscow. J Obstetri Gynecol Pediatrics 1(136).

10. URMANOV YuM, Mavlonov UKh (2013) Passatite delays and various developmental disorders in boys in Bukhara and the Bukhara region in the conditions of iodine deficiency " Zhurn theoretical and clinical medicine Tashkent, 4: 12-15

\section{ISSN: 2574-1241}

DOI: $10.26717 /$ BJSTR.2021.38.006080

Urmanova Yu M. Biomed J Sci \& Tech Res

This work is licensed under Creative Commons Attribution 4.0 License

Submission Link: https://biomedres.us/submit-manuscript.php
11. Festa A, Umano GR, Del Giudice EM, Grandone A (2020) Genetic evaluation of patients with delayed puberty and congenital hypogonadotropic hypogonadism: Is it worthy of consideration. Front Endocrinol (Lausanne) 11: 253.

12. Bozzola M, Bozzola E, Montalbano C, Stamati FA, Ferrara P, et al. (2018) Delayed puberty versus hypogonadism: a challenge for the pediatrician. Ann Pediatr Endocrinol Metab 23(2): 57-61.

13. Delange $F$ (2001) Iodine deficiency as a cause of brain damage. Postgrad Med J 77(906): 217-220.

14. Zhu J, Feldman HA, Eugster EA, Fechner PY, Nahata L, et al. (2020) Practice variation in the management of girls and boys with delayed puberty. Endocr Pract 26(3): 267-284.

15. Roa J, Barroso A, Ruiz-Pino F, Vázquez MJ (2018) Metabolic regulation of female puberty via hypothalamic AMPK-kisspeptin signaling. Proc Natl Acad Sci U S A 115(45): E10758-E10767.

16. Howard SR, Dunkel L (2019) Delayed puberty-phenotypic diversity, molecular genetic mechanisms, and recent discoveries. Endocr Rev 40(5): 1285-1317.

17. Howard SR (2019) The genetic basis of delayed puberty. Front Endocrinol (Lausanne) 10: 423.

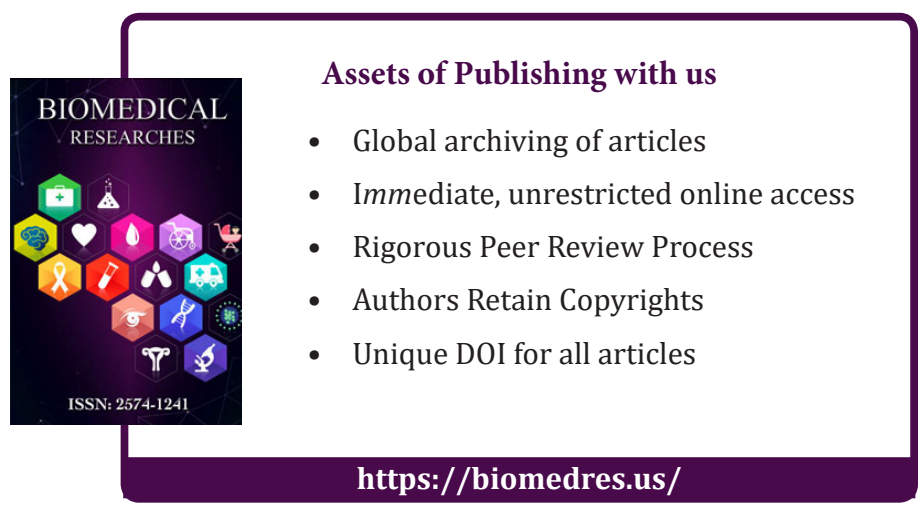

